\title{
The Implications of Absorption Cost Accounting and Production Decisions for Future Firm Performance and Valuation
}

Article in Contemporary Accounting Research · February 2010

DOI: $10.1111 /$ j.1911-3846.2010.01030.x

CITATIONS

18

3 authors, including:

\section{Mahendra Gupta}

Washington University in St. Louis

39 PUBLICATIONS 1,557 CITATIONS

SEE PROFILE
READS

123

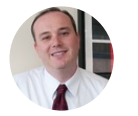

Mikhail Pevzner

University of Baltimore

40 PUBLICATIONS 236 CITATIONS

SEE PROFILE

Some of the authors of this publication are also working on these related projects:

Project

The Emergence of Virtual Card Payments: Data Highlights Changes in North American Commercial

Payment Practices View project

Project

Crowdfunding View project 


\title{
The implications of absorption cost accounting and production decisions for firms' future performance and valuation
}

\author{
Mahendra Gupta \\ guptam@wustl.edu \\ Mikhail Pevzner \\ pevznerm@wustl.edu
}

Chandra Seethamraju **

seethamraju@wustl.edu

November 2005

We appreciate the helpful comments of seminar participants at New York University, University of Arkansas and participants at the accounting department brown bag at Washington University.

** Corresponding Author. \#1 Olympian Way, Campus Box 1133, Washington University, Saint Louis, MO 63130. 


\begin{abstract}
In this paper, we evaluate a comprehensive set of inventory related signals, the association between those signals and future firm performance and how the stock market responds to these signals. There is mixed evidence in the literature on how the market perceives and reacts to inventory build-ups and possible income manipulation. Lev and Thiagarajan (1993) conclude that the stock market views their measure of excess inventory growth as a negative signal, while Jiambalvo et al. (1997) find evidence that stock returns are positively associated with their measure of overproduction. In our view, the stock market perception of overproduction should also be affected by the materiality of the fixed costs that get absorbed into ending inventory. We provide evidence that future accounting performance (as measured by ROA) of high relative fixed cost/high overproduction firms is significantly negatively associated with overproduction, while this relationship is positive for other firms. We find that the stock market reacts in a rational manner and that there is a substantial reduction in the positive valuation impact of overproduction for firms with high relative fixed costs and high overproduction.

We also examine the impact of order backlog, as also its interaction with overproduction and high relative fixed cost structure. We find that, in general, for firms that have a "bad news" order backlog signal, overproduction is more negatively associated with future performance (as measured by ROA) relative to firms that did not have such a signal. We also report strong evidence that the market reacts rationally and discounts reported earnings of firms with 'bad news' order backlog signals, relative to other firms.
\end{abstract}




\section{Introduction}

In this paper, we evaluate a comprehensive set of inventory related signals, the association between those signals and future firm performance and how the stock market responds to these signals. Most management accounting texts discuss the fact that manufacturing firms can increase reported income by producing goods in excess of the quantity required to meet current demand (see, for e.g. Horngren, Datar and Foster, 2002, p.287). One reason for such potentially suboptimal behavior is that if managers are compensated based on reported operating income, they may be tempted to over-produce in order to increase reported operating income. Other reasons for firms to indulge in this type of opportunistic behavior could include stock market pressures to meet analysts' forecasts of earnings. Roychowdhury (2004) investigates whether firms succeed in avoiding losses by engaging in managing sales via, perhaps, relaxing credit terms and offering sales discounts, reduction of discretionary expenditures, such as advertising and R \& D, and inventory over-production. He reports that inventory over-production is positively associated with the avoidance of losses and this effect is more pronounced among manufacturing firms.

Since most firms use absorption costing (as opposed to variable costing), such overproduction results in allocation of part of current period fixed manufacturing overhead to ending inventory rather than to cost of goods sold. This in turn reduces cost of goods sold and increases reported income for the period. Therefore, the component of earnings attributable to over-production may reflect potential opportunistic behavior and may be viewed as being of lower quality than the remaining component of earnings. There is mixed evidence in the literature on how the market perceives and reacts to inventory build-ups and possible income manipulation. Lev and Thiagarajan (1993) examine the value-relevance of multiple signals of future firm performance identified in Value Line analyst reports. One of the signals of interest to them was 
the excess of annual percentage inventory growth over annual percentage sales growth. Lev and Thiagarajan conclude that the stock market views excess inventory growth as a negative signal, indicating possible production for inventory and/or problems with inventory obsolescence and turnover. Abarbanell and Bushee (1997) confirm that excess inventory growth had a negative association with future earnings.

It is also possible that managers may produce more than current period demand in order to be able to meet future anticipated demand. In such an instance, overproduction would relate to future firm performance and would not reflect opportunistic behavior. Jiambalvo, Noreen and $\underline{\text { Shevlin (1997) }}$ (henceforth referred to as JNS) explore this issue using a large sample of manufacturing firms and find evidence that stock returns are positively associated with their measure of overproduction, CPAI (change in percent of production added to inventory) ${ }^{1}$. In their view, this finding is consistent with stock market participants viewing CPAI as a leading positive indicator of firm performance. JNS only examine the quantity added to inventory. The literature, however, has not examined the impact of the interaction of the components of overproduction which impact the income statement- the quantity added to inventory and the relative fixed costs level which impacts the dollar amount absorbed in ending inventory.

In this paper, we provide one of the first sets of empirical results that show that the arguments of both Lev and Thiagarajan (1993) and JNS (1997) can coexist. In our view, the stock markets perception of CPAI should also be affected by the amount of fixed costs that get absorbed into ending inventory. In other words, if a firm had a high fixed cost structure and produced in excess of current demand, the impact on income for such a firm would be much greater than for a firm which did not have a high fixed cost structure. In this study, we propose a

\footnotetext{
${ }^{1}$ JNS also control for the Lev and Thiagarajan (1993) measure of abnormal inventory growth. They show that both signals are incremental to each other.
} 
parsimonious proxy (called, Fixed Asset Intensity) for a firms' fixed cost structure, measured as the ratio of a firms' gross fixed assets to total assets in a given year. We identify high relative fixed cost firms as those firms with Fixed Asset Intensity greater than the median Fixed Asset Intensity for all firms in the firms' 2 digit SIC code in that year. We identify high over-production firms as those firms with CPAI greater than the median CPAI for all firms in the firms' 2 digit SIC code in that year. We provide evidence that future accounting performance (as measured by ROA) of high relative fixed cost/high overproduction firms is significantly negatively associated with overproduction, while this relationship is positive for other firms. More importantly, to the extent that such firms add to inventory opportunistically, they could be masking performance/operating problems by indulging in this behavior in the current period. It would not be a sustainable strategy for firms to overproduce over multiple periods when the overproduction is not matched by future revenues. Therefore, the positive impact of overproduction on performance (for firms producing opportunistically) in the current period should be reversed in future periods.

We hypothesize that the stock market discounts the positive impact of CPAI found in JNS for firms with high relative fixed costs (and high overproduction) compared to other firms. The reason for this is that this component of earnings should be of lower 'quality', given that for these firms a material amount of current fixed overhead has been absorbed into ending inventory rather than cost of goods sold. We find that the stock market reacts in a rational manner and report strong evidence in support of our hypothesis. There is a substantial reduction in the positive valuation impact of CPAI for firms with high relative fixed costs and high overproduction. The market seems to make adjustments for the lower 'quality' of reported earnings. 
The stock markets perception of overproduction (which is essentially an inventory buildup) could also be impacted by signals related to future sales expectations. Order Backlog is an additional inventory related disclosure that potentially captures future sales expectation, since it is the dollar value of unfilled sales orders by the firm at the end of the period. ${ }^{2}$ Rajgopal et al. (2003) report that order backlog is value-relevant and has a positive association with future earnings. We examine the impact of order backlog, as also its interaction with CPAI (another leading indicator of future performance, as per JNS) and high relative fixed asset intensity.

We find that, in general, for firms that have a "bad news" order backlog signal, CPAI is significantly more negatively associated with future performance (as measured by ROA) relative to other firms. In addition, we provide strong evidence that the market reacts rationally and discounts reported earnings of firms with 'bad news' order backlog signals, relative to other firms.

Levitt (1998) voiced concerns that the motivation for firms to meet Wall Street earnings expectations could be overriding common sense business practices. This paper falls into the stream of literature that examines income manipulation via 'real decisions', i.e. when management intervenes in the "normal" earnings process via potentially sub-optimal managerial decisions, such as excessive production, scaling back research and development expenditures (Bushee (1998), Dechow and Sloan (1991)), or timing of asset sales (Bartov, 1993).

Our paper contributes to the literature in three ways. First, our study fills a gap in the literature by explicitly examining whether the market understands the implications of absorption costing and that inventory over-production could have subsequent period performance effects. In addition, un-justified over-production could be evidence of short-sighted decisions by managers, and understanding whether the market identifies such sub-optimal decisions is an important

\footnotetext{
${ }^{2}$ Firms are required to disclose Order Backlog when the number is deemed to be material.
} 
question. Second, we examine an important additional dimension of inventory overproduction which was, hitherto, not explicitly examined by the literature - relative fixed cost structure of firms and its interaction with inventory build-ups in impacting reported net income. Finally, we examine a comprehensive set of inventory related variables and study them in conjunction with each other, and not in isolation, as the literature has tended to do so. This enables us to develop a richer understanding of how the stock market perceives the various inventory related signals and their interactions with each other.

The rest of the paper is organized as follows: in Section 2, we provide the motivation and develop the hypotheses. In Section 3, we describe our sample, and in Section 4, we describe our findings for the main sample. In section 5, we describe our findings for the order backlog sample. Conclusions are provided in Section 6.

\section{Motivation and Hypotheses development}

\subsection{Motivation}

The issue of absorption costing vs. variable costing methods has not received substantial attention in the empirical financial accounting literature. Instead, the research has primarily focused on the issues of choice of valuation models for inventories (LIFO vs. FIFO, see, for example Kinney and Wempe (2004), Hunt et al. (2000), Pincus (1997), among more recent studies).

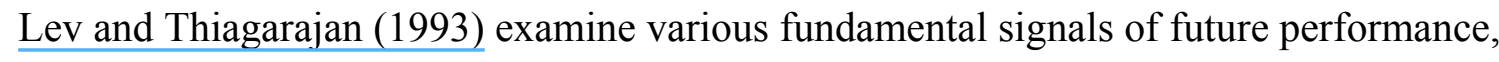
such as excess receivables growth over sales growth, excess inventory growth over sales growth, order backlog, capital expenditures, gross margin, etc., in relation to the contemporaneous returns. Their motivation for using these signals was based on analyst reports from Value Line 
analysts, wherein these fundamental signals were discussed. According to Lev and Thiagarajan (1993), these analysts view excess percentage change in inventory over percentage change in contemporaneous sales as a negative signal, reflecting an unjustified or unsustainable build-up of inventories. Lev and Thiagarajan (1993) find that excess inventory build-ups are negatively associated with current returns, consistent with analysts' assessment of this signal. Abarbanell and Bushee (1997) report that inventory build-ups are negatively associated with future performance. Roychowdhry's (2004) measure of inventory over-production is closely related to the Lev and Thiagrajan (1993) abnormal inventory growth measure. He uses the Dechow et al. (1998) accrual model to derive the expected cost of goods sold and expected annual inventory change as a function of the firms' prior period sales and sales change. Roychowdhury's (2004) measure of abnormal production explicitly incorporates the cost of and prior sales history in the production costs expectation model. It does not, however, explicitly model how fixed costs are factored into inventory valuation.

Another study that has attempted to more explicitly tie variations in fixed cost structure to inventory valuation is JNS (1997). They provide an analytical model of the differential between absorption and variable costing earnings and develop an explicit measure of the effect of "production for inventory" on this differential. They call this measure Change in Percentage of Production Added to Inventory (CPAI). ${ }^{3}$ JNS show that CPAI is positively associated with contemporaneous CARs, incremental to the annual earnings surprise. Moreover, they show that CPAI is informative incremental to the Lev and Thiagarajan (1993) excess inventory growth measure, suggesting that these two signals are independent of each other. JNS interpret their results as indicating that $\mathrm{CPAI}$ is viewed by the market as providing favorable information about future performance, incremental to the unexpected earnings and past sales information. JNS also

\footnotetext{
${ }^{3}$ For the derivation of CPAI refer to the Appendix section of JNS (pages 91-93).
} 
attempt to allow fixed manufacturing overhead to vary across firms by running industry-based regressions and controlling for firm size. They do not find a differential impact of CPAI in these regressions.

The findings of Lev and Thigarajan (1993) and Abarbanell and Bushee (1997) on one hand, and JNS (1997) on the other hand, seem to indicate that the two different measures of overproduction examined in these studies are viewed differently by the market. The former two studies report that their measure is viewed as a negative signal, while JNS report that their measure is viewed as a positive signal by the market. In addition, JNS suggest that these two signals appear to be incremental to each other. The variable used in Lev and Thiagarajan (1993) compares changes in inventory to contemporaneous changes in sales. However, there could be changes in inventory due to anticipated changes in sales in future periods and their variable does not capture that effect. None of these studies controls explicitly for the absorption of fixed manufacturing overhead (FMO). We argue that if FMO is brought into the analysis, situations where these variables could provide different signals can be studied. Since the two variables (Lev and Thiagarajan (1993) and JNS (1997)) are measured differently, we further study the variable used in JNS (namely, CPAI) and examine under what conditions CPAI is viewed positively and when it is viewed negatively by the market.

\subsection{Impact of Firms' Fixed manufacturing overhead}

For a manufacturing firm, the biggest reason for fixed manufacturing overhead is its own production and manufacturing facilities. The higher the firm's investment in fixed assets associated with inventory production, the higher is the amount of expense associated with these fixed assets and is considered fixed manufacturing overhead allocated to inventory. Such expense includes depreciation charges, repair and maintenance expenses on the manufacturing facilities, 
and the like. These charges are not separately disclosed in the financial statements as they are included in the cost of goods sold and in the ending inventory balance. ${ }^{4}$ The JNS model indicates that $\mathrm{CPAI}$ is one of the two components impacting the differential between absorption costing earnings and variable costing earnings. The second component is firms' fixed manufacturing overhead. JNS explicitly assume that fixed manufacturing overhead (as a percentage of the deflator, market value of equity) of all firms' is a cross-sectional and time-series constant. They attempt to control for fixed costs by re-estimating their analysis across industries (2 digit SIC code level) and size deciles, and their results are unchanged in that analysis. JNS acknowledge that their approach has limitations since it does not explicitly incorporate firms' fixed cost properties in the analysis.

We feel that fixed manufacturing overhead (FMO) is an important factor that needs to be integrated into the analysis, while being cognizant of the fact that this number is not available to outside users of financial statements. Hence, we model FMO's cross-sectional variation in our tests in the following manner. We use the ratio of gross fixed assets to total assets of the firm in year $t$, as a measure of a firm's fixed cost structure and call this ratio Fixed Asset Intensity (henceforth referred to as FAI). We use gross fixed assets since gross fixed assets are free of allocation rules used for depreciation and provide for a more homogenous way to compare this variable across firms. It is also not clear which number investors are focusing on in order to determine capital investment and its impact on fixed costs 5 . Thus, FAI is a proxy for the magnitude of FMO allocated to inventories in the end of the period.

\footnotetext{
${ }^{4}$ Recently, as part of its International Convergence Project, FASB issued Statement 151 that becomes effective for companies with year end after June 15, 2005, that modifies full absorption costing accounting to exclude certain abnormal amounts of the idle facility expense, freight, handling costs and wasted materials to be expensed in the current period.

${ }^{5}$ In addition, we also use the ratio of net fixed assets to total assets as an alternative measure of Fixed asset intensity. We redo the main tests reported in the paper using this variable and the results are essentially unchanged.
} 
Figure 1 demonstrates the empirical distribution of the coefficient of variation of FAI within industries. A great deal of within industry variation is apparent in the coefficient of variation of FAI. Therefore, the assumption of a constant FMO cross-sectionally and over time potentially limits the inferences of JNS's empirical analysis. ${ }^{6}$ Hence, we expect that for each firm in a particular industry, there is a benchmark based upon which the market judges whether the firm has high relative fixed costs. We take into account the relative position of a firm using this ratio within a given industry. The median FAI in a particular year and industry (four digit SIC code) is used as a benchmark to separate high manufacturing overhead firms from low manufacturing overhead firms. We categorize firms that are above the median in terms of FAI as firms with high fixed manufacturing overhead and those below the median as firms with low manufacturing overhead. ${ }^{7}$ We expect that obtaining further understanding of the interaction of firms' relative fixed cost levels with excess quantity of inventory produced in the end of the period (CPAI) will help us better understand how the market values firms whose earnings are materially impacted by fixed manufacturing overhead absorption. Similar to FAI, we categorize firms that are above the median (in a particular year and industry (four digit SIC code)) in terms of CPAI as firms with high overproduction and those below the median as firms with low overproduction.

\subsection{Hypothesis Development}

In general, JNS showed that CPAI is viewed as a positive signal by the market. We are specifically interested in firms with high Fixed Asset Intensity and high CPAI. These are firms

\footnotetext{
${ }^{6}$ Coefficient of variation (CV), a commonly used statistical metric, is equal to the ratio of the distribution's standard deviation to its mean, and thus represents a summary measure of relative variation within a distribution of a variable. In case of FAI, we compute the within-industry CV across industries and years and present the summary distribution in Figure 1.

${ }^{7}$ We also evaluate firms' Fixed Asset Intensity without regard to SIC codes. The results in the paper are invariant to this modification. This is consistent with the results in Fairfield et al. (2005).
} 
for which the impact of overproduction on earnings should be of greater magnitude. Therefore, the component of earnings attributable to overproduction could be of 'lower quality'. More importantly, to the extent that such firms add to inventory opportunistically, they could be masking performance/operating problems by indulging in this behavior in the current period. It would not be a sustainable strategy for firms to overproduce over multiple periods when the overproduction is not matched by future sales. Therefore, the positive impact of overproduction on performance (for firms producing opportunistically) in the current period should be reversed in future periods. This leads to our first hypothesis which we test with the objective of establishing that this phenomenon occurs in our sample:

Hypothesis 1: Future accounting performance (as measured by ROA) for firms with high

CPAI and high FAI is negatively associated with overproduction in the current period.

If the stock market is concerned with the "quality of earnings" aspect of inventory overproduction and is able to identify firms where such over-production has a material impact on earnings, then a lower valuation on CPAI should be observed for these firms. As stated above, this is because the component of earnings attributable to overproduction would be perceived to be of 'lower quality'. The firms whose earnings should be most impacted by inventory overproduction are those with high CPAI and high fixed manufacturing overhead (high FAI). We hypothesize that the observed positive valuation of CPAI documented in JNS will be weaker among firms with both high CPAI and high Fixed Asset Intensity. This leads to our second hypothesis :

Hypothesis 2: The stock market reaction to inventory overproduction, as measured by the relation between CPAI and contemporaneous abnormal returns, is more negative for firms 
with high overproduction (above the median CPAI) and high fixed manufacturing overhead (above the median FAI).

\subsection{Research design}

We estimate the following equation to test Hypothesis 1:

$$
\begin{aligned}
& \text { ROA }_{\mathrm{i}, \mathrm{t}+1}=\gamma_{0}+\gamma_{1} * \mathrm{CPAI}_{\mathrm{it}}+\gamma_{2} * \mathrm{FAI}_{\mathrm{it}}+\gamma_{3} * \mathrm{MED}_{-} \mathrm{FAI}_{\mathrm{it}}+\gamma_{4} * \mathrm{MED}_{-} \mathrm{CPAI}_{\mathrm{it}}+\gamma_{5} \\
& * \mathrm{INTMED}_{\mathrm{it}}+\gamma_{6} * \mathrm{LT}_{\mathrm{it}}+\gamma_{7} * \mathrm{MB}_{\mathrm{it}}+\varepsilon_{\mathrm{it}}(1), \text { where, }
\end{aligned}
$$

$\mathrm{ROA}_{i, t+1}$, is the year $\mathrm{t}+1$ earnings before extraordinary items (Compustat data\#18),

deflated by the average total assets in year t. Following JNS, CPAI is defined as

$\frac{\Delta I n v_{a b s_{t}}}{C O G S_{a b s_{t}}+\Delta I n v_{a b s_{t}}}-\frac{\Delta I n v_{a b s_{t-1}}}{C O G S_{a b s_{t-1}}+\Delta I n v_{a b s_{t-1}}}$, where $\Delta I n v$ represents annual inventory change in years $t$ and $t-1$, respectively, calculated based on total (absorption-costing based) inventory value (Compustat data\#3), and COGS represents firm's cost of goods sold (Compustat data\#41). FAI denotes Fixed Asset Intensity defined as $\frac{\text { Gross Fixed Assets }_{t}}{\text { Total Assets }_{t}}$ and is measured as a ratio of the firm's gross fixed assets to total assets in year $\mathrm{t}$ (data\#7/data\#6). MED_CPAI denotes a dummy variable equal to 1 if $\mathrm{CPAI}_{\text {it }}$ exceeds the median for all firms in firm i's four digit SIC code in year $t$, and zero otherwise. MED_FAI denotes a dummy variable equal to 1 if $\mathrm{FAI}_{\mathrm{it}}$ exceeds median FAI for all firms in firm i's SIC code in year t, and zero otherwise. The variable INTMED represents an interaction term measuring the differential valuation of CPAI for high Fixed Asset Intensity Firms and High CPAI firms, that is $\mathrm{INTMED}_{\mathrm{it}}={\mathrm{MED} \_F A I_{i t}} * \mathrm{MED} \_\mathrm{CPAI}_{\mathrm{it}} * \mathrm{CPAI}_{\mathrm{it}}$. The coefficient on this variable is the primary focus of our analysis. MB is the market to book ratio calculated as market value of equity divided by book value of equity, at the end of year $t$. This variable is included because risk is a factor that potentially explains future firm performance and we explicitly control for it by including the market to book ratio. 
Our prediction for Hypothesis 1 is that CPAI has a positive association with future ROA $\left(\gamma_{1}>0\right)$ and that this association is weaker for high CPAI/high Fixed Asset Intensity firms $\left(\gamma_{5}<0\right)$. We do not make a prediction of the average association between FAI and ROA or on the sign of the coefficients for MED_CPAI or MED_FAI.

We also control for Abnormal Inventory Growth (LT1), a variable investigated by Lev and Thiagarajan (1993) and further analyzed by Abarbanell and Bushee (1997), defined as $\frac{\Delta I n v_{t}}{I n v_{t-1}}-\frac{\Delta \text { Sales }_{t}}{\text { Sales }_{t-1}}$, i.e., the annual percentage change in inventory minus annual percentage change in sales. We expect $\mathrm{ROA}_{t+1}$ and LT1 to be negatively associated $\left(\gamma_{6}<0\right)$ consistent with Abarbanell and Bushee (1997).

Next, we estimate the following equation in order to test hypothesis 2 .

$$
\begin{aligned}
& \mathrm{CAR}_{\mathrm{it}}=\beta_{0}+\beta_{1} * \mathrm{CPAI}_{\mathrm{it}}+\beta_{2} * \mathrm{FAI}_{\mathrm{it}}+\beta_{3} * \mathrm{MED}_{-} \mathrm{FAI}_{\mathrm{it}}+ \\
& \beta_{4} * \mathrm{MED}_{-} \mathrm{CPAI}_{\mathrm{it}}+\beta_{5} * \mathrm{INTMED}_{\mathrm{it}}+\beta_{6} * \mathrm{UEARN}+\beta_{7} * \mathrm{LT}_{\mathrm{it}}+\varepsilon_{\mathrm{it}} \text { (2), where, }
\end{aligned}
$$

CAR, or cumulative abnormal return, is composed of monthly size-adjusted abnormal returns for year $\mathrm{t}$, cumulated starting 3 months after the beginning of year $t$, and ending three months after year $t$ ends. UEARN denotes unexpected earnings, defined as the annual earnings' change from year $t-1$ to $t$, deflated by the firm's market value of equity at the end of year $t-1$. All other variables are as defined earlier.

Consistent with JNS, we predict a positive association between CPAI and CAR, that is $\beta_{1}$ $>0$ and consistent with prior literature on Earnings Response Coefficients, we predict $\beta_{6}>0$. The coefficient on INTMED is the primary focus of our analysis. Consistent with Hypothesis 2, we predict $\beta_{5}<0$. We do not make a prediction of the average association between FAI and CAR or the sign of the coefficients on MED_CPAI or MED_FAI. 


\section{Data and descriptive statistics.}

\subsection{Data}

We closely follow the sample selection criteria in JNS. We start with the sample of all manufacturing firms (SIC Codes 2000-3999) in the 2003 CRSP/Compustat merged dataset for years 1975-2003. JNS focused only on NYSE firms, while we include NASDAQ firms as well. ${ }^{8}$ We obtain monthly abnormal return data from CRSP and require that the firms in our sample have sufficient data to compute CPAI, UEARN, LT1, and FAI. Firms with negative book values are excluded since negative book value firms likely represent firms in serious financial distress which the market potentially values differently. Following standard practice, we truncate each of the independent variables at one percent of the tails of the respective distributions. Our final sample (hereafter referred to as the "Main sample") consists of 42679 firm-year observations. We provide descriptive statistics and correlation analyses for the Main Sample in Table 1and Table 2, respectively.

Later in the paper we include order backlog in our analysis. Since order backlog data is available for a much smaller set of firm-years, we construct another sample (hereafter referred to as "Backlog sample") with the only restriction being the availability of backlog data for the sample period. The backlog sample has 18746 observations after a truncation procedure similar to that described earlier.

\subsection{Descriptive Statistics}

Table 1 provides descriptive statistics for all variables used in the regression analyses and for other size variables, such as Market Value of Equity (MVE) and Market-to-Book (MB) ratio.

\footnotetext{
${ }^{8}$ We replicate JNS result on the sub-sample of non-NASDAQ firms and on our sample, and the results are consistent across samples.
} 
The summary statistics for both MVE and MB indicate that the Main sample corresponds closely to the overall characteristics of the Compustat database. Our sample is slightly biased towards larger manufacturing firms (both mean and median of MVE in our sample are a little higher than means and medians of MVE for all Compustat firms). In all, both MVE and MB descriptive statistics indicate that our sample is composed of larger, more mature manufacturing firms. Descriptive statistics for ROA indicate that for firms in the Main sample, the average profitability is low (mean ROA is 0.02 ). An analysis of the distribution of ROA suggests that our sample has an approximately equal composition of profit and loss firms. ${ }^{9}$

The comparison with results in JNS indicates that the distribution of CPAI in our study and JNS is not very different. JNS (We) report a mean CPAI of $-0.06(-0.01)$, median of -0.02 (0.001 ) and standard deviation of 0.11 (0.12). Our study covers the period from 1975-2003 while the period covered in JNS is 1975-1992. In addition, our study also includes NASDAQ firms, while the JNS study does not. ${ }^{10}$

The distribution of unexpected earnings in our main sample and JNS' sample is also very similar. They (we) report mean and median unexpected earnings of $0.004(0.01)$ and $0.01(0.00)$, respectively. The standard deviations for unexpected earnings in the two samples are also very similar.

The Fixed Asset Intensity, or FAI, variable constitutes the focus of our analysis. This variable serves as a proxy for the comparative fixed cost structure of the firm, and is the primary object of our study. The mean of 0.52 indicates that, on average, manufacturing firms' fixed assets constitute $52 \%$ of their entire asset base.

\footnotetext{
${ }^{9}$ This is a larger composition of loss firms than recent studies have reported. For example, Dopuch et al. (2005) document that loss firms constitute $36 \%$ of their sample in the period 1988-2003.

${ }^{10}$ We re-perform original JNS analysis on both our sample and their original sample. JNS' result holds in both cases. We do not exclude NASDAQ firms since there is no a priori reason to do so, and ex-post exclusion of NASDAQ firms from the analysis may lead to exchange listing bias described in Kraft et al. (2005).
} 
Finally, Abnormal Inventory Growth (LT1) has a mean and median of 0 and -0.01 , indicating that on average firms in the Main sample tend not to have excess inventory build-ups. This is not surprising, since we should not expect to see inventory build-ups on average, especially in the 1990s, when firms have been increasingly adopting Just-In-Time inventory management systems.

The correlation analysis for the Main sample is summarized in Table 2. For primary variables of interest, CPAI exhibits a Spearman (Pearson) correlation of $0.10(0.12)$ with CAR. That is, CPAI is perceived to be a signal that demonstrates good news. FAI and CAR are negatively correlated though the correlation coefficient is not high, potentially reflecting the market's possible negative view of high capital intensity. We find low positive correlation between CPAI and FAI (0.03 Pearson and 0.01 Spearman) and low negative correlation between FAI and LT1 (-0.02, for both Pearson and Spearman), suggesting that these corresponding pairs of variables represent independent signals of firm performance. LT1 and CPAI are significantly positively correlated. LT1 represents a value of abnormal inventory growth, while CPAI represents the excess production quantity. Since inventory quantity is a component of its total balance sheet value, high correlation is expected. It is also interesting that the Spearman correlation of FAI and MB is -0.16 . Since Spearman correlation coefficient measures rank correlation, this may likely indicate that the market assigns lower growth expectations to firms that have high fixed asset intensity. However, the corresponding Pearson correlation is a low 0.01 , indicating that the product moment correlation is low, that is, there is no a priori evidence of the linear relation between these two variables. Hence, it is possible that the relation Spearman correlation coefficient captures is more pronounced for only higher ranks of FAI variable, 
indicating that such firms have higher excess capacity and are not expected to have stronger future growth.

\section{Main Sample results}

We provide the OLS estimates of equation (1) for the Main Sample in Table 3, Panel A with and without time fixed effects. We present the results of two regressions (Model 1 without and model 2 with annual fixed effects) of next year's ROA on a set of explanatory variables. In Model 1, the coefficient on FAI is positive and significant (0.04), reflecting, on average, a positive association between fixed asset investment and future performance. The coefficient on CPAI is also significant and positive (0.18), consistent with results reported in JNS. The coefficient on LT1 is negative and significant (-0.03), consistent with Abarbannell and Bushee (1997).

The coefficient on out variable of interest, INTMED, is strongly negative and significant (-0.32), indicating that over-production by firms with high fixed cost structure is negatively associated with future accounting performance. The net impact of CPAI on these firms' future earnings is negative, as measured by the sum of the coefficients $\gamma_{1}+\gamma_{5}=-0.14$. In other words, firms that have 'capitalized' manufacturing overhead in inventory in prior periods are likely to experience future negative performance. The results are similar for Model 2. These initial findings provide support for hypothesis 1 and indicate that the phenomenon of reversal is performance caused by overproduction is manifested in our sample. ${ }^{11}$

\footnotetext{
${ }^{11}$ We also include, as a control, the average firm ROA over the prior 3 years to control for mean reversal in ROA and the flavor of our results is essentially unchanged. We chose the current research design because it is the case that CPAI impacts current period ROA, as well and hence we made a choice not to include current period ROA and its components in the same regression.
} 
Next, we estimate equation 2 to tests hypothesis 2 . The results presented in Table 3, panel B show that, consistent with the findings of JNS, the market views CPAI as a positive signal, as indicated by the positive and significant coefficient on CPAI in both regressions. Consistent with results in the ERC literature, the coefficient on unexpected earnings is positive and significant ( 0.88 and 0.90 in Model 1 and Model 2, respectively). In addition, we find a negative and significant coefficient on LT1 (-0.10 in both models) consistent with Lev and Thiagarajan (1993). We observe a negative and significant coefficient on FAI (-0.08, in both models), indicating that, on average, the higher the fixed asset intensity, the lower the abnormal returns that a firm earns. At the same time, interestingly, the positive and significant coefficient on MED_FAI (0.01) indicates that the firms that have above median fixed asset intensity in their industry/year earn higher abnormal returns. This coefficient, however, is small as compared to the others reported. ${ }^{12}$ Consistent with JNS, the positive and significant coefficient on MED_CPAI reflects market's general positive view of increased production, as a positive signal of future sales.

The coefficient on INTMED, which is the main variable of interest to us, is negative and significant in both models $(-0.30 /-0.32)$. In other words, the market discounts the weight placed on CPAI for firms that have both high fixed cost structure and high end of the year production. The market seems to understand the impact of absorption costing (resulting in higher reported earnings) for firms that have high fixed costs and high end-of-the-year over-production. Therefore, the market reacts more cautiously to earnings of such firms, resulting in lower abnormal returns. This finding demonstrates that markets appear to react in a rational manner in adjusting for fixed costs absorption effects. This finding is consistent with our prior finding of a negative association between overproduction for high fixed manufacturing overhead firms and future performance. This suggests that the market rationally discounts CPAI for such firms. In

\footnotetext{
${ }^{12}$ This variable is not significant in the subsequent analyses.
} 
fact, the entire positive valuation impact of CPAI disappears for this sub-sample of firms. This provides support for hypothesis 2 .

To summarize the results so far, CPAI, in general, is a positive signal. Additional evidence presented indicates that future accounting performance (as measured by ROA) is negatively associated with CPAI for firms which have a high relative fixed cost structure and high relative overproduction. However, the market rationally discounts (given our future accounting performance results) CPAI for firms with high relative fixed cost structure and high relative overproduction.

\section{Order Backlog Sample}

\subsection{Order Backlog}

Order backlog represents the dollar value of orders that are unfulfilled and are scheduled to be executed in future periods. Rajgopal et al. (2003) note that order backlog numbers are economically significant enough to expect investors to pay attention to them when forecasting a firm's future earnings. There are two main factors that could influence the magnitude of backlog orders. The first factor is the orders contracted for, but unfilled due to demand for firms' products. The second factor is the efficiency with which firms utilize manufacturing capacity, which allows then to either fill orders in a timely manner or result in the creation of a backlog.

Order backlog value is only available for a limited set of firms since it is required to be disclosed in the Management Discussion and Analysis (MDA), only if it is material. Moreover, SEC disclosure requirements do not exactly specify what exactly "material" amount means, and this likely leads to the reduced reliability of reported order backlog amounts. Rajgopal et al. (2003) document that order backlog has a positive association with contemporaneous returns. In 
addition, they report that order backlog is positively associated with future earnings. Rajgopal et al. (2003) also report that the market perhaps places excessive emphasis on the order backlog signal, since it is not clear to what extent order backlog predicts firms' future expected sales, or relates to some other firm-specific factors that lead to inefficiencies in deliveries around year-end. Liu, Livnat, and Ryan (1996) provide evidence that backlog order disclosures are useful in predicting future sales. Hence, to the extent order backlog supports the increased end-of-the-year inventory balance, it could be viewed as a signal of better "quality" of ending inventory. This could also result in higher 'quality' of reported earnings. Since CPAI and order backlog are both related to future sales, in this section we further examine how these variables interact.

The nature of interaction between order backlog and other inventory signals has not been previously examined in the literature. In the first part of the paper we show that the association between overproduction (CPAI) and future firm performance (as measured by ROA), is significantly negative. We build on prior results by conjecturing that if the signal from order backlog is not supportive of the inventory build up then that would be considered a 'bad news' signal. If the order backlog signal relative to other firms in the industry is conflicting with the other firm-specific inventory signals, in the sense that order backlog signals lower future sales, and other inventory signals indicate potentially higher future sales, we expect that there should be a stronger negative association between overproduction (CPAI) and future firm performance. This leads to our next hypothesis:

Hypothesis 3: The negative association between overproduction and future performance for high CPAI/high relative fixed asset firms is more pronounced for firms that have a 'bad news' backlog order signal. 
The finding of Rajgopal et al. (2003) that the market over-prices implications of order backlog for future earnings suggests that future firm performance might also be impacted. Following up on hypothesis 3 , we expect that the market would penalize overproduction for firms with high overproduction/high relative fixed costs more when the order backlog signal denotes 'bad news' (i.e. not supportive of the inventory build up) than otherwise.

Hypothesis 4: The market penalizes overproduction to a greater degree for high overproduction/high fixed cost firms in situations when the order backlog order signal is 'bad news' relative to other firms.

\subsection{Order Backlog results}

In order to test Hypothes4s 3 and 4, we modify equations 1 and 2 by including additional variables. We include a variable BACKLOG_SALES which is measured as order backlog (Compustat data item \# 98) at the end of year $t$ deflated by sales (Compustat data item \#12) for year t. We also include a variable, BACKLOG*CPAI to capture the average interaction effects of backlog order and overproduction (CPAI). In addition, we construct a dummy variable BACKLOG_NEWS, which is equal to 1 if BACKLOG_SALES for a given firm in year $\mathrm{t}$ is less than the median of BACKLOG_SALES for firms in the same four digit SIC code, and zero otherwise. This dummy variable is used to partition the sample and run regression tests as described later.

In untabulated results, we find that the summary descriptive statistics for all variables overlapping between the Main and Backlog samples are very similar with one notable exception. Firms in the Backlog sample tend to be much smaller than the firms in the main sample. The mean market capitalization for firms in the Backlog sample is close to half that for firms in the Main sample (\$556.27 million as compared to \$1,241 million). We also find that on average, 
order backlog constitutes about $38 \%$ of current year sales as measured by BACKLOG_SALES. The distribution of BACKLOG_SALES is very similar to that reported by Rajgopal et al. $(2003) .^{13}$

We replicate the future performance test (with fixed effects) reported in Table 3, panel A for the smaller order backlog sample. The results are reported in Table 4, Panel A in the column headed 'Equation 1'. The results are entirely consistent with the results reported in Table 3, panel A, indicating that the results hold for this sample, as well. We then estimate the modified version of Equation 1, by including the order backlog variable (BACKLOG_SALES) and BACKLOG*CPAI (its interaction with CPAI). The objective of this test is to get a baseline result for order backlog for our sample. The results are presented in Table 4, Panel A under the column headed 'Modified Equation 1'. The results are consistent with those previously reported for the Main sample. INTMED has a negative and significant coefficient (-0.26), indicating that CPAI of firms with high CPAI and high fixed cost intensity on average is negatively associated with future performance (the net impact that CPAI has for these firms' future ROA is $-0.10=0.16-0.26$ (where 0.16 is the overall CPAI coefficient and -0.26 is the coefficient on INTMED). In addition, we note that the order backlog signal in general is a positive signal, while its interaction with CPAI (BACKLOG*CPAI) is positive but insignificant.

Next, we replicate the market reaction test (with fixed effects) reported in Table 3, panel B for the smaller order backlog sample. The results are reported in Table 4, Panel B in the column headed 'Equation 2'. The results are entirely consistent with the results reported in Table 3, panel B, indicating that the result hold for this sample, as well. We then estimate the modified version of Equation 2, by including the order backlog variable (BACKLOG_SALES) and

\footnotetext{
${ }^{13}$ The backlog orders variable in Rajgopal et al.'s analysis is deflated by assets, while we deflate our variable by sales since we believe that investors focus on backlog orders as a ratio of current sales. Untabulated robustness checks reveal that backlog variable distribution is invariant to the choice of the deflator.
} 
BACKLOG*CPAI (its interaction with CPAI). The results are presented in Table 4, Panel B under the column headed 'Modified Equation 2'. INTMED has a negative and significant coefficient (-0.24), indicating that the market strongly discounts CPAI for firms with high fixed asset intensity and high CPAI. In addition, we note that the coefficient on CPAI is positive and significant (0.28), in general, which is consistent with its positive impact on future performance.

In order to test hypotheses 3 and 4, we partition the sample by BACKLOG_NEWS and then estimate modified equations 1 and 2 for these two sub-samples. The results for estimating the modified equation 1 are presented in Table 5, panel A. The results when the order backlog signal is categorized as 'bad news' (i.e., where BACKLOG_NEWS=1), are presented in the columns to the right in the table and labeled as such. In the columns to the left, we present the results from estimating modified equation 1, when BACKLOG_NEWS=0. In both sub-samples CPAI has a positive and significant coefficient, consistent with the result in JNS. The coefficient on INTMED, our variable of interest, is negative and significant in both sub-samples. However, the magnitude of the coefficient is substantially more negative (-0.35) for the 'bad news' order backlog sub-sample versus (-0.22) for the other firms sub-sample. The magnitude of the coefficient is about $50 \%$ more negative for the 'bad news' sub-sample providing support for hypothesis 3 . This indicates that the association between overproduction and future performance is more negative for high overproduction/high fixed assets firms that have a 'bad news' order backlog signal than for other firms where the order backlog signal is not bad news. We should note however, that we base our inferences on the magnitude of the coefficient on INTMED in the two regressions by sub-sample.

The results for estimating modified equation 2 are presented in Table 5, panel B. Under the heading BACKLOG_NEWS=1, we provide the results where the order backlog signal is 
categorized as 'bad news' and under the heading BACKLOG_NEWS=0, the results when the order backlog signal is categorized as not denoting 'bad news'. The results again show that, in general, CPAI is a positive signal in both sub-samples. In general, our focus, however, is on the variable INTMED. The coefficient on INTMED is strongly negative and significant for the 'bad news' order backlog signal sub-sample. The coefficient on the other sub-sample, however, is not significant. The net impact for the order backlog 'bad news' sample is the sum of the coefficients on CPAI and INTMED, which would be $0.25-0.43=-0.18(0.29-0.05=0.24)$. This result suggests that for high overproduction/high fixed costs firms, overproduction (CPAI) is significantly discounted by the stock market when the order backlog signal does not support the inventory build-up, providing support for hypothesis 4 . In the cases where the order backlog signal is not bad news, the market does not discount CPAI. In fact, for such firms CPAI continues to be a positive signal. These results indicate that the market reacts rationally to the various inventory signals - overproduction, fixed cost structure and order backlog - and takes into account the interactions between them. The results for market reaction for the bad news order backlog subsample reported in Table 5, panel B are entirely consistent with the future performance results reported in Table 5, panel A.

\section{Conclusions}

In this paper, we evaluate a comprehensive set of inventory related signals, the interactions between them and implications of these signals for future firm performance. We also examine how the stock market responds to these signals. Initially, we extend the findings in JNS and Roychowdhury (2004) by explicitly controlling for cross-sectional variation in firms' fixed cost structure and thus providing a more complete description of absorption costing effects on 
firms' earnings. We explicitly demonstrate that firms' fixed cost structure plays a role in the inventory valuation, and show that the stock market views firms' fixed costs structure as one additional factor in its valuation of inventory accruals. Hence, we provide a more complete picture to the valuation and future accounting performance implications of inventory accruals previously identified in the literature. More importantly, we provide a link between management accounting and financial accounting research by explicitly showing that firms' capital investment policies have direct implications for firms' inventory valuation and future performance.

In this study, we propose a measure of firms' fixed cost structure, represented by the firms' fixed asset intensity. We note that this measure exhibits cross-sectional and time-series variation, and based on that measure, we categorize firms into high and low relative fixed cost firms. In addition, we use the overproduction measure (CPAI) developed in JNS and categorize firms into high and low overproduction firms. Our study also adds to the findings of prior studies that address aspects of inventory valuation, such as JNS (1997) and Lev and Thiagarajan (1993). Both these studies utilize measures of change in inventories and examine market reactions to these measures. JNS find that overproduction is viewed as a positive signal by the stock market.

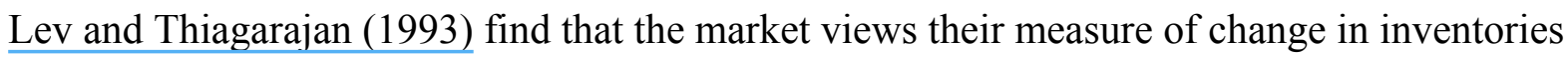
(relative to contemporaneous sales) as a negative signal. In this paper, we provide one of the first sets of empirical results showing that the findings of both JNS (1997) and Lev and Thigarajan (1993) can coexist. Focusing on the measure suggested by JNS (CPAI), we examine the circumstances under which this change in inventory measure is viewed positively and negatively.

Our results suggest that, in general, $\mathrm{CPAI}$ is positively associated with future firms performance, as measured by ROA. However, for firms in the high relative fixed costs and high overproduction category, the association between CPAI and ROA is in fact negative and 
significant, suggesting that the overproduction is on average opportunistic for such firms. This is because it would not be a sustainable strategy for firms to overproduce over multiple periods when the overproduction is not matched by future revenues. Therefore, the positive impact of overproduction on performance (for firms producing opportunistically) in the current period should be reversed in future periods.

In addition, we find that the market reaction is consistent with the future impact of overproduction. In general (consistent with JNS), the stock market views CPAI as a positive signal. However, the valuation impact of CPAI is substantially reduced for firms in the high relative fixed costs and high overproduction categories. The market seems to make adjustments for the 'lower' quality of reported earnings.

We also examine the role of order backlog and its interaction with overproduction and high relative fixed cost structure for the sample of firms for which order backlog is available. We find that CPAI is negatively associated with future performance (as measured by ROA) to a greater degree for firms that have high relative fixed cost/high overproduction firms that have a 'bad news' backlog signal (i.e., an overproduction signal that does not support an inventory build-up) relative to firms that do not have a 'bad news' order backlog signal. In addition, for the sample of firms for which order backlog is available, we find that the market reacts rationally and that the negative association between CPAI and abnormal returns documented for high overproduction/high relative fixed cost firms is driven by firms with a 'bad news' order backlog signal. In other words, firms where overproduction is not supported by the order backlog signal are penalized by the market. The market views overproduction for such firms as 'opportunistic' and the relationship between CPAI and abnormal returns turns negative. 


\section{References:}

Abarbanell, J. and B. Bushee (1997). Fundamental Analysis, Future Earnings and Stock Prices. Journal of Accounting Research, 35(1), 1-24

Bartov, E. (1993). The timing of asset sales and earnings manipulation. Accounting Review, 68(4), 840-856.

Bushee, B. (1998). The influence of institutional investors on myopic R\&D investment behavior. Accounting Review, 73(3), 305-333

Dechow P., S.P. Kothari. and R. Watts. (1998). The relation between earnings and cash flows. Journal of Accounting and Economics 25, 133-168

Dechow, P. and R. Sloan (1991). Executive incentives and the horizon problem: an empirical investigation. Journal of Accounting and Economics, 14(1), 51-89

Dopuch, N., C. Seethamarju, W. Xu (2005). The accrual anomaly within the context of profit and loss firms. Working Paper. Washington University and SUNY Buffalo.

Fairfield, P., S. Ramnath, and T. Yohn (2005). Does industry level analysis improve profitability and growth forecasts? Working paper. Georgetown University.

Horngreen, C., S. Datar, and G. Foster (2002). Cost Accounting-A Managerial Emphasis. Prentice Hall.

Jiambalvo, J, E. Noreen and T. Shevlin (1997). Incremental information content of the change in percent of production added to inventory. Contemporary Accounting Research, $14(1), 69-97$

Kraft A., A. Leone and C. Wasley (2005). An analysis of theories and explanations offered for the mis-pricing of accruals and accrual components. Working Paper. University of Rochester.

Kinney, M. and W. Wempe (2004). JIT Adoption: The effects of LIFO reserves and financial reporting and tax incentives. Contemporary Accounting Research 21(3), 603-638.

Hunt, A., S. Moyer and T. Shevlin (2000). Do LIFO Manage Inventories and Accruals to Meet Tax and Financial Reporting Objectives? Working Paper. University of Auckland and University of Washington.

Lev, B. and R. Thiagarajan (1993). Fundamental Information Analysis. Journal of Accounting Research (Autumn), 190-215. 
Levitt, A. (1998). "The Numbers Game”. Speech at NYU Center for Law and Business. Available at http://www.sec.gov/news/speech/speecharchive/1998/spch220.txt

Liu, C, J. Livnat, and S. Ryan (1996). Forward-looking financial information: the order backlog as a predictor of future sales. The Journal of Financial Statement Analysis, (Fall), 89-99.

Pincus, M. (1997). Stock price effects of the allowance of LIFO for tax purposes. Journal of Accounting and Economics, 23(3), 283-308.

Rajgopal, S., T. Shevlin, M. Venkatachalam (2003). Does the stock market fully appreciate the implications of leading indicators for future earnings? Evidence from order backlog. Review of Accounting Studies, 8, 461-492.

Roychowdhury, S. (2004). Management of earnings through the manipulation of real activities that affect cash flow from operations. Working Paper. MIT Sloan School of Management. 


\section{Table 1}

\section{Descriptive Statistics}

\section{Main Sample}

\begin{tabular}{c|ccccc}
\hline Variable (N=42679) & Mean & Median & Std Dev & $\begin{array}{c}\text { Lower } \\
\text { Quartile }\end{array}$ & $\begin{array}{c}\text { Upper } \\
\text { Quartile }\end{array}$ \\
\hline CAR & 0.02 & -0.00 & 0.49 & -0.25 & 0.25 \\
MVE & 1263.37 & 76.63 & 7970.61 & 19.28 & 388.66 \\
MB & 2.77 & 1.53 & 27.23 & 0.94 & 2.58 \\
ROA & 0.02 & 0.05 & 0.16 & 0.00 & 0.09 \\
BV & 428.64 & 51.21 & 1804.38 & 14.66 & 209.25 \\
CPAI & -0.008 & -0.001 & 0.12 & -0.05 & 0.04 \\
UEARN & 0.01 & 0.008 & 0.15 & -0.03 & 0.04 \\
FAI & 0.52 & 0.48 & 0.27 & 0.32 & 0.69 \\
LT1 & 0.00 & -0.01 & 0.33 & -0.14 & 0.13 \\
& & & & & \\
MVE-all Compustat & 936.86 & 54.86 & $7,929.29$ & 13.07 & 255.98 \\
firms & & & & & \\
MB Ratio-all & 3.26 & 1.44 & 223 & 0.81 & 2.65 \\
Compustat firms & & & & & \\
\hline
\end{tabular}

\section{Variables’ Definitions:}

CAR-cumulative monthly size adjusted return for the year $t$, cumulated over 12 months starting 3 months after the beginning of year $t$.

MVE- market value of equity

MB- market-to-book ratio (not used in the analysis; is included for descriptive purpose only)

ROA- earnings before extraordinary items, deflated by the average assets at year $t$

BV- book value of equity

CPAI-Cumulative Percentage Added to Inventory, per JNS.

UEARN-annual earnings change, deflated by MVE

FAI-fixed assets deflated by total assets

LT1-Variable used in Lev and Thiagarajan (1993) representing excess inventory growth over sales growth. It is calculated as percentage of annual change in inventory less percentage annual sales change. 
Table 2

Correlations for the Main Sample.

\begin{tabular}{|c|c|c|c|c|c|c|c|c|c|}
\hline $\mathrm{N}=42679$ & CAR & MVE & MB & ROA & BV & CPAI & UEARN & FAI & LT1 \\
\hline CAR & - & $0.02 * * *$ & $0.02 * * *$ & $0.17 * * *$ & 0.001 & $0.10 * * *$ & $0.29 * * *$ & $-0.04 * * *$ & $-0.04 * * *$ \\
\hline MVE & $0.12 * * *$ & - & $0.02 * * *$ & $0.07 * * *$ & $0.73 * * *$ & $0.01 *$ & -0.004 & $0.04 * * *$ & -0.004 \\
\hline MB & $0.24 * * *$ & $0.42 * * *$ & - & $-0.08 * * *$ & 0.001 & 0.00 & 0.00 & $-0.01 * *$ & -0.006 \\
\hline ROA & $0.27 * * *$ & $0.33 * * *$ & $0.28 * * *$ & - & $0.06^{* * *}$ & $0.13^{* * *}$ & $0.25^{* * *}$ & $0.02 * * *$ & $0.008 *$ \\
\hline BV & $0.03 * * *$ & $0.92 * * *$ & $0.09 * * *$ & $0.27^{* * *}$ & - & 0.007 & $-0.01 * *$ & $0.13 * * *$ & -0.009 \\
\hline CPAI & $0.12 * * *$ & $0.03 * * *$ & $0.05 * * *$ & $0.13^{* * *}$ & $0.01 * *$ & - & $0.16^{* * *}$ & $0.03 * * *$ & $0.43 * * *$ \\
\hline UEARN & $0.39 * * *$ & $0.02 * * *$ & $0.10 * * *$ & $0.40 * * *$ & $-0.02 * * *$ & $0.19 * * *$ & - & -0.005 & $-0.09 * * *$ \\
\hline FAI & $-0.03 * * *$ & $0.11 * * *$ & $-0.16^{* * *}$ & $-0.02 * * *$ & $0.19 * * *$ & $0.01 * * *$ & $-0.02 * * *$ & - & $-0.02 * * *$ \\
\hline LT1 & $-0.09 * * *$ & -0.006 & $-0.02 * * *$ & $-0.01 * *$ & -0.002 & $0.54 * * *$ & $-0.15 * * *$ & $-0.02 * * *$ & - \\
\hline
\end{tabular}

(Pearson Correlations above the diagonal and Spearman correlations below the diagonal)

\section{Variable Definitions:}

CAR-cumulative monthly size adjusted return for the year $t$, cumulated over 12 months starting 3 months after the beginning of year $t$.

MVE- market value of equity

MB- market-to-book ratio (not used in the analysis; is included for descriptive purpose only)

ROA- earnings before extraordinary items, deflated by the average assets at year $t$

BV- book value of equity

CPAI-Cumulative Percentage Added to Inventory, per JNS.

UEARN-annual earnings change, deflated by MVE

FAI-fixed assets deflated by total assets

LT1-Variable used in Lev and Thiagarajan (1993) representing excess inventory growth over sales growth. It is calculated as percentage annual change in inventory less percentage annual sales change

*** Significant at 0.01 level;** Significant at 0.05 level; *Significant at 0.1 level 
Table 3:

Tests of Future Performance and Valuation Effects (Main Sample)

Panel A: Impact of overproduction on Future Performance (Equation 1)

Dependent Variable: FUT_ROA (ROA ${ }_{t+1}$

\begin{tabular}{l|c|c|c|c|c}
\hline \multirow{2}{*}{ Variable } & \multirow{2}{*}{$\begin{array}{c}\text { Expected } \\
\text { (N=38422)) }\end{array}$} & $\begin{array}{c}\text { Model 1 (without time } \\
\text { fixed effects) }\end{array}$ & \multicolumn{2}{c}{$\begin{array}{c}\text { Model 2(with time fixed } \\
\text { effects) }\end{array}$} \\
\cline { 3 - 6 } & $\begin{array}{c}\text { Sign } \\
\text { Coefficient } \\
\text { estimate }\end{array}$ & p-value & $\begin{array}{c}\text { Coefficient } \\
\text { estimate }\end{array}$ & p-value \\
\hline INTERCEPT & $?$ & 0.009 & 5.05 & 0.06 & 0.00 \\
CPAI & + & 0.18 & 0.00 & 0.17 & 0.00 \\
FAI & $?$ & 0.04 & 0.00 & 0.03 & 0.00 \\
MED_FAI & $?$ & -0.00 & 0.10 & -0.00 & 0.57 \\
MED_CPAI & $?$ & -0.00 & 0.69 & -0.00 & 0.93 \\
INTMED & $?$ & -0.32 & 0.00 & -0.29 & 0.00 \\
LT1 & - & -0.03 & 0.00 & -0.03 & 0.00 \\
MB & $?$ & -0.00 & -11.51 & -0.00 & $\mathbf{0 . 0 0}$ \\
\hline R ${ }^{2}$ & & 0.02 & & 0.05 & \\
\hline
\end{tabular}

Variable Definitions:

CAR-cumulative monthly size adjusted return for the year $t$, cumulated over 12 months starting 3 months after the beginning of year $t$.

CPAI-Cumulative Percentage Added to Inventory, per JNS.

FAI-fixed assets deflated by total assets

MED_FAI-dummy variable $=1$ if annual FAI $>$ MEDIAN(FAI) for firms in the same 4 digit SIC code

MED_CPAI-dummy variable=1 if annual CPAI > MEDIAN(CPAI) for firms in the same 4 digit SIC code

INTMED=MED_FAI*MED_CPAI*CPAI.

LT1-Variable used in Lev and Thiagarajan (1993) representing excess inventory growth over sales growth calculated as percentage annual change in inventory less percentage annual sales change.

$\mathrm{MB}$ - is the market to book ratio. 
Table 3

Panel B: Test of market reaction to inventory overproduction (Equation 2)

Dependent Variable: CAR (Cumulative abnormal Returns)

\begin{tabular}{|c|c|c|c|c|c|}
\hline \multirow[b]{2}{*}{ Variable } & \multirow[b]{2}{*}{\begin{tabular}{|c|} 
Expected \\
Sign
\end{tabular}} & \multicolumn{2}{|c|}{$\begin{array}{c}\text { Model } 1 \text { (without time } \\
\text { fixed effects) }\end{array}$} & \multicolumn{2}{|c|}{$\begin{array}{c}\text { Model } 2 \text { (with time fixed } \\
\text { effects) }\end{array}$} \\
\hline & & \begin{tabular}{|c|} 
Coefficient \\
estimate
\end{tabular} & p-value & \begin{tabular}{|c|} 
Coefficient \\
estimate
\end{tabular} & p-value \\
\hline INTERCEPT & $?$ & 0.04 & 0.00 & -0.01 & 0.40 \\
\hline CPAI & + & 0.34 & 0.00 & 0.37 & 0.00 \\
\hline FAI & $?$ & -0.08 & 0.00 & -0.08 & 0.00 \\
\hline MED_FAI & $?$ & 0.01 & 0.00 & 0.01 & 0.05 \\
\hline MED_CPAI & $?$ & 0.03 & 0.01 & 0.03 & 0.00 \\
\hline INTMED & $?$ & -0.30 & 0.00 & -0.32 & 0.00 \\
\hline UEARN & + & 0.88 & 0.00 & 0.90 & 0.00 \\
\hline LT1 & - & -0.10 & 0.00 & -0.10 & 0.00 \\
\hline $\mathrm{R}^{2}$ & & 0.10 & & 0.11 & \\
\hline
\end{tabular}

Variable Definitions:

CAR-cumulative monthly size adjusted return for the year $t$, cumulated over 12 months starting 3 months after the beginning of year $t$.

CPAI-Cumulative Percentage Added to Inventory, per JNS.

FAI-fixed assets deflated by total assets

MED_FAI-dummy variable $=1$ if FAI $>$ annual, SIC code MEDIAN(FAI)

MED_CPAI-dummy variable $=1$ if CPAI $>$ annual, SIC code MEDIAN(CPAI)

INTMED $=$ MED_FAI*MED_CPAI*CPAI.

UEARN-annual earnings change, deflated by MVE

LT1-Variable used in Lev and Thiagarajan (1993) representing excess inventory growth over sales growth.

It is calculated as percentage annual change in inventory less percentage annual sales change. 
Table 4 (Backlog Sample)

Panel A: Impact of overproduction on Future Performance

Dependent Variable: FUT_ROA $\left(\mathrm{ROA}_{\mathrm{t}+1}\right)$

\begin{tabular}{l|c|c|c|c|c}
\hline & & \multicolumn{2}{|c|}{ Equation 1 } & \multicolumn{2}{c}{ Modified Equation 1 } \\
\hline \multirow{2}{*}{ Variable (N=18746) } & $\begin{array}{c}\text { Expected } \\
\text { Sign }\end{array}$ & $\begin{array}{c}\text { Coefficient } \\
\text { estimate }\end{array}$ & p-value & $\begin{array}{c}\text { Coefficient } \\
\text { estimate }\end{array}$ & p-value \\
\hline INTERCEPT & $?$ & 0.06 & 0.00 & 0.06 & 0.00 \\
CPAI & + & 0.16 & 0.01 & 0.16 & 0.00 \\
FAI & $?$ & 0.02 & 0.00 & 0.02 & 0.00 \\
BACKLOG_SALES & + & & & 0.01 & 0.00 \\
BACKLOG*CPAI & $?$ & & & 0.01 & 0.37 \\
MED_FAI & $?$ & -0.00 & 0.31 & -0.00 & 0.2 \\
MED_CPAI & $?$ & -0.00 & 0.73 & -0.00 & 0.65 \\
INTMED & $?$ & -0.25 & 0.00 & -0.26 & 0.00 \\
LT1 & - & -0.03 & 0.00 & -0.04 & 0.00 \\
MB & & -0.00 & 0.00 & -0.00 & 0.00 \\
\hline R $^{2}$ & & 0.05 & & 0.023 & \\
\hline
\end{tabular}

\section{Variable Definitions:}

CAR-cumulative monthly size adjusted return for the year $t$, cumulated over 12 months starting 3 months after the beginning of year $t$.

CPAI-Cumulative Percentage Added to Inventory, per JNS.

FAI-fixed assets deflated by total assets

BACKLOG_SALES-order backlog deflated by current year sales

MED_FAI-dummy variable $=1$ if annual FAI $>$ MEDIAN(FAI) for firms in the same 4 digit SIC code MED_CPAI-dummy variable $=1$ if annual CPAI $>$ MEDIAN(CPAI) for firms in the same 4 digit SIC code INTMED=MED_FAI*MED_CPAI*CPAI.

UEARN-annual earnings change, deflated by MVE

LT1-Variable used in Lev and Thiagarajan (1993) representing excess inventory growth over sales growth. It is calculated as percentage annual change in inventory less percentage annual sales change. $\mathrm{MB}$ - is the market to book ratio. 
Table 4

Examination of Valuation and Future Performance Effects in the Backlog Sample Panel B - Dependent Variable: CAR

\begin{tabular}{l|c|c|c|c|c}
\hline & & \multicolumn{2}{|c|}{ Equation 2 } & \multicolumn{2}{c}{ Modified Equation 2 } \\
\hline & & Expected & Coefficient & & Coefficient \\
Variable & Sign & estimate & p-value & estimate & p-value \\
INTERCEPT & $?$ & -0.00 & 0.74 & -0.03 & 0.06 \\
CPAI & + & 0.37 & 0.00 & 0.28 & 0.00 \\
FAI & $?$ & -0.07 & 0.00 & -0.07 & 0.00 \\
BACKLOG_SALES & + & & & 0.07 & 0.00 \\
BACKLOG*CPAI & & & & 0.32 & 0.00 \\
MED_FAI & $?$ & 0.00 & 0.53 & 0.00 & 0.53 \\
MED_CPAI & $?$ & 0.03 & 0.00 & 0.03 & 0.00 \\
INTMED & $?$ & -0.22 & 0.00 & -0.24 & 0.00 \\
UEARN & + & 0.93 & 0.00 & 0.93 & 0.00 \\
LT1 & - & -0.14 & 0.00 & -0.15 & 0.00 \\
R & & 0.12 & & 0.13 & \\
\hline
\end{tabular}

\section{Variable Definitions:}

FUT_ROA-Year $t+1$ earnings before extraordinary items deflated by year $t$ average assets.

CPAI-Cumulative Percentage Added to Inventory, per JNS.

FAI-fixed assets deflated by total assets

BACKLOG_SALES-order backlog deflated by current year sales

MED_FAI-dummy variable $=1$ if annual FAI $>$ MEDIAN(FAI) for firms in the same 4 digit SIC code

MED_CPAI-dummy variable $=1$ if annual CPAI > MEDIAN(CPAI) for firms in the same 4 digit SIC code

INTMED $=$ MED_FAI*MED_CPAI*CPAI.

UEARN-annual earnings change, deflated by MVE

LT1-Variable used in Lev and Thiagarajan (1993) representing excess inventory growth over sales growth. It is calculated as percentage annual change in inventory less percentage annual sales change. 
Table 5

Panel A: Impact of overproduction on Future Performance when order backlog is a 'bad news'signal Dependent Variable: FUT_ROA $\left(\right.$ ROA $\left._{t+1}\right)$

\begin{tabular}{|c|c|c|c|c|c|}
\hline \multirow[b]{2}{*}{ Variable } & \multirow[b]{2}{*}{$\begin{array}{l}\text { Expected } \\
\text { Sign }\end{array}$} & \multicolumn{2}{|c|}{$\begin{array}{c}\text { BACKLOG_NEWS=0 } \\
\text { N=10476 }\end{array}$} & \multicolumn{2}{|c|}{$\begin{array}{c}\text { BACKLOG_NEWS }=1 \\
N=8260\end{array}$} \\
\hline & & $\begin{array}{c}\text { Coefficient } \\
\text { estimate }\end{array}$ & p-value & $\begin{array}{c}\text { Coefficient } \\
\text { estimate }\end{array}$ & p-value \\
\hline INTERCEPT & $?$ & 0.03 & 0.00 & 0.01 & 0.09 \\
\hline CPAI & + & 0.10 & 0.00 & 0.17 & 0.00 \\
\hline FAI & $?$ & 0.00 & 0.16 & 0.03 & 0.00 \\
\hline BACKLOG_SALES & + & 0.00 & 0.02 & 0.06 & 0.00 \\
\hline BACKLOG*CPAI & $?$ & 0.03 & 0.09 & -0.03 & 0.63 \\
\hline MED_FAI & $?$ & -0.00 & 0.32 & -0.00 & 0.91 \\
\hline MED_CPAI & $?$ & 0.00 & 0.79 & -0.00 & 0.11 \\
\hline INTMED & $?$ & -0.22 & 0.00 & -0.35 & 0.00 \\
\hline LT1 & - & -0.03 & 0.00 & -0.03 & 0.00 \\
\hline $\mathrm{MB}$ & - & -0.00 & 0.00 & -0.00 & 0.00 \\
\hline$\overline{\mathrm{R}^{2}}$ & & & 0.03 & & 0.04 \\
\hline
\end{tabular}




\section{Variable Definitions:}

CAR-cumulative monthly size adjusted return for the year $t$, cumulated over 12 months starting 3 months after the beginning of year $\mathrm{t}$.

CPAI-Cumulative Percentage Added to Inventory, per JNS.

FAI-fixed assets deflated by total assets

BACKLOG_SALES-order backlog deflated by current year sales

MED_FAI-dummy variable $=1$ if annual FAI $>$ MEDIAN(FAI) for firms in the same 4 digit SIC code

MED_CPAI-dummy variable=1 if annual CPAI > MEDIAN(CPAI) for firms in the same 4 digit SIC code

INTMED=MED_FAI*MED_CPAI*CPAI.

BACKLOG_NEWS=1 if annual BACKLOG_SALES $<$ MEDIAN (BACKLOG_SALES) for firms in the same 4 digit SIC code

UEARN-annual earnings change, deflated by MVE

LT1-Variable used in Lev and Thiagarajan (1993) representing excess inventory growth over sales growth. It is calculated as percentage annual change in inventory less percentage annual sales change. 
Table 5

Panel B- Examination of Valuation and Future Performance Effects controlling for when order backlog is a 'bad news' signal Dependent Variable: CAR

\begin{tabular}{|c|c|c|c|c|c|}
\hline \multirow[b]{2}{*}{ Variable } & \multirow[b]{2}{*}{ Expected Sign } & \multicolumn{2}{|c|}{ BACKLOG_NEWS=0 } & \multicolumn{2}{|c|}{ BACKLOG_NEWS=1 } \\
\hline & & $\begin{array}{c}\text { Coefficient } \\
\text { estimate }\end{array}$ & p-value & $\begin{array}{c}\text { Coefficient } \\
\text { estimate }\end{array}$ & p-value \\
\hline$\overline{\text { INTERCEPT }}$ & $?$ & 0.05 & 0.01 & -0.02 & 0.17 \\
\hline CPAI & + & 0.29 & 0.00 & 0.25 & 0.00 \\
\hline FAI & $?$ & -0.11 & 0.00 & -0.03 & 0.21 \\
\hline BACKLOG_SALES & + & 0.05 & 0.00 & 0.08 & 0.00 \\
\hline BACKLOG*CPAI & $?$ & 0.28 & 0.00 & 0.30 & 0.18 \\
\hline MED_FAI & $?$ & 0.01 & 0.19 & -0.00 & 0.87 \\
\hline MED_CPAI & $?$ & 0.03 & 0.00 & 0.04 & 0.00 \\
\hline INTMED & $?$ & -0.05 & 0.67 & -0.43 & 0.00 \\
\hline UEARN & + & 0.97 & 0.00 & 0.85 & 0.00 \\
\hline LT1 & - & -0.15 & 0.00 & -0.16 & 0.00 \\
\hline $\mathrm{R}^{2}$ & & 0.13 & & 0.10 & \\
\hline
\end{tabular}




\section{Variable Definitions:}

CAR-cumulative monthly size adjusted return for the year $t$, cumulated over 12 months starting 3 months after the beginning of year $t$.

CPAI-Cumulative Percentage Added to Inventory, per JNS.

FAI-fixed assets deflated by total assets

BACKLOG_SALES-order backlog deflated by current year sales

MED_FAI-dummy variable $=1$ if annual FAI $>$ MEDIAN(FAI) for firms in the same 4 digit SIC code

MED_CPAI-dummy variable=1 if annual CPAI > MEDIAN(CPAI) for firms in the same 4 digit SIC code

INTMED=MED_FAI*MED_CPAI*CPAI.

BACKLOG_NEWS=1 if annual BACKLOG_SALES $<$ MEDIAN (BACKLOG_SALES) for firms in the same 4 digit SIC code

UEARN-annual earnings change, deflated by MVE

LT1-Variable used in Lev and Thiagarajan (1993) representing excess inventory growth over sales growth. It is calculated as percentage annual change in inventory less percentage annual sales change. 
Figure 1

Cross-sectional distribution of within industry coefficient of variation of FAI

Frequency distribution of coefficient of variation of FASSG_ASS across industries and years

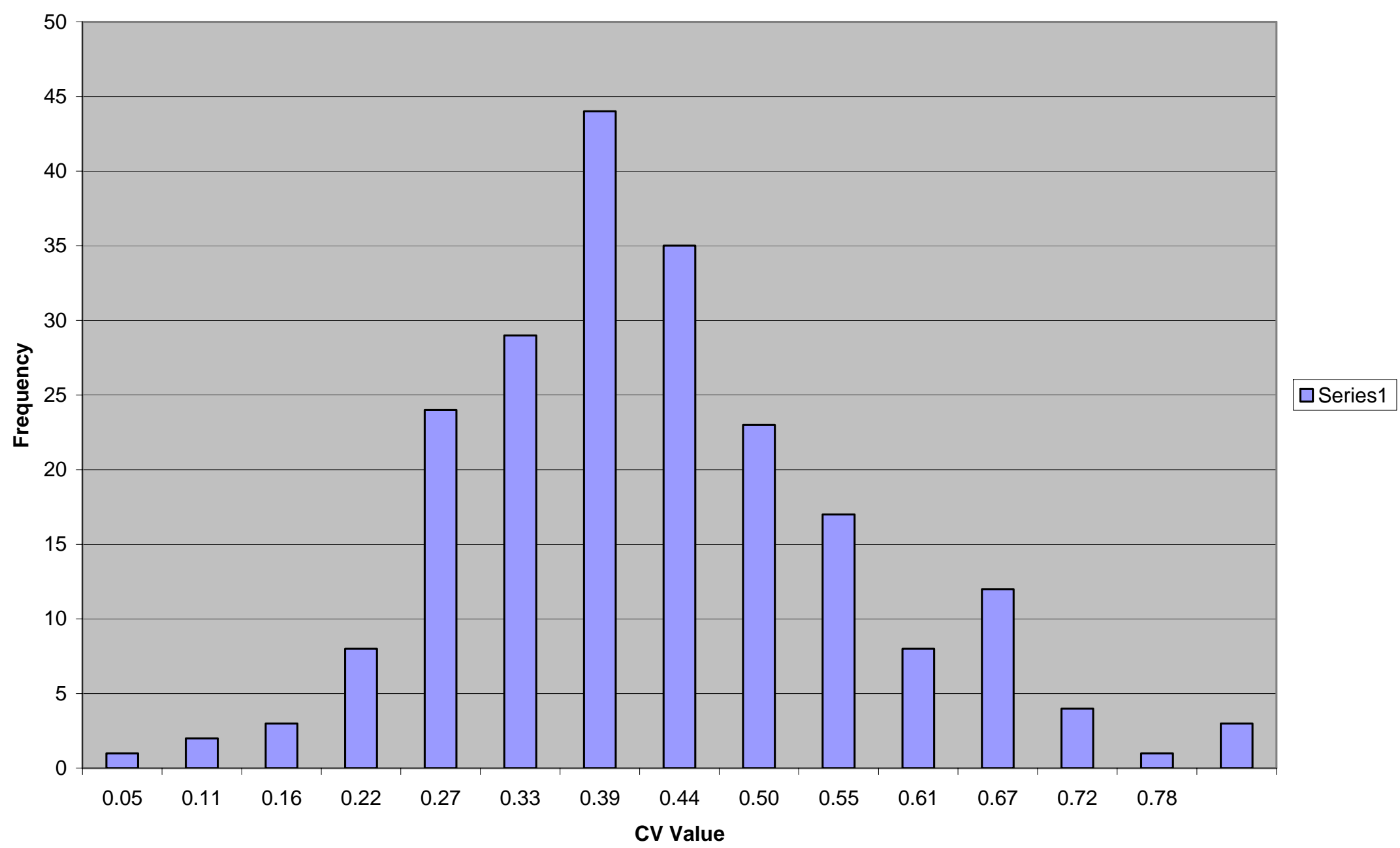

